\title{
PREVENTION OF ACCIDENTS
}

\author{
BY
}

\section{H. M. VERNON}

London

The industrial medical officer, in addition to his duties in organizing and supervising first-aid services for the treatment of injuries incurred in factories and other industrial establishments, is often able to play an important part in limiting or preventing the accidents responsible for these injuries. His scope of action is normally an indirect one, dependent on advice to the management about the conditions of work in the factory and on the personal qualities of the workers, but we shall see that it may be of considerably greater importance than anything that can be effected by mechanical improvements such as the better safeguarding of moving machinery. This side of accident prevention is the province of the engineer and does not concern the medical officer, but many of the duties commonly assigned to 'safety' engineers relate to the psychology of the workers and should therefore be of interest to the medical officer.

Before describing the influence of various conditions on accident causation it will be well to quote some statistical information about the frequency of accidents of various types, for it is only in this way that we shall be able to grasp the magnitude of the problem. For the information adduced we are chiefly indebted to the invaluable data published every year in the Reports of the Chief Inspector of Factories.

\section{Frequency of Accidents}

Table 1 is taken from the Annual Report of H.M. Chief Inspector for the year 1943.*

TABLE 1

\section{ALL REPORTABLE ACCIDENTS}

\begin{tabular}{|c|c|c|c|c|c|}
\hline & Year & $\begin{array}{l}\text { Adult } \\
\text { males }\end{array}$ & $\begin{array}{c}\text { Adult } \\
\text { females }\end{array}$ & $\begin{array}{c}\text { Male } \\
\text { young } \\
\text { persons }\end{array}$ & $\begin{array}{c}\text { Female } \\
\text { young } \\
\text { persons }\end{array}$ \\
\hline $\begin{array}{l}1938 \\
1940 \\
1941 \\
1942 \\
1943 \\
\text { Per } \\
\text { crea } \\
\text { over }\end{array}$ & 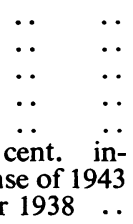 & $\begin{array}{l}134,752 \\
173,228 \\
191,343 \\
203,865 \\
200,651\end{array}$ & $\begin{array}{l}14,626 \\
23,766 \\
42,857 \\
71,244 \\
73,065\end{array}$ & $\begin{array}{l}22,922 \\
26,492 \\
27,757 \\
29,028 \\
27,623\end{array}$ & $\begin{array}{r}7,803 \\
8,493 \\
9,341 \\
10,493 \\
9,805\end{array}$ \\
\hline
\end{tabular}

It relates to all reportable accidents, both fatal and non-fatal, i.e. to 'compensation' accidents, such compensation being payable only for accidents causing at least three full days' absence from work. It will be seen that between 1938 and 1943 the accidents to adult males increased by 49 per cent., but those to adult females by no less than 400 per cent. The tremendous increase incurred by women was due especially to the very much larger number of women employed, and also to the fact that many of them were not only inexperienced workers but had been transferred to the more dangerous occupations previously confined to men. This increase of risk is suggested by the data in Table 2 (taken from the 1941 Report), which shows the approximate accident rate per 1000 employed in 1938 and 1941.

TABLE 2

ACCIDENT RATE PER 1000 EMPLOYED

\begin{tabular}{|c|c|c|c|}
\hline & 1938 & 1941 & $\begin{array}{l}\text { Per cent. } \\
\text { increase }\end{array}$ \\
\hline $\begin{array}{l}\text { Adult males .. } \\
\text { Adult females } \\
\text { Male young persons .. } \\
\text { Female young persons }\end{array}$ & $\begin{array}{l}40 \\
9 \cdot 5 \\
43 \cdot 0 \\
14 \cdot 5\end{array}$ & $\begin{array}{l}50 \\
18 \\
52 \\
18\end{array}$ & $\begin{array}{l}25 \\
90 \\
21 \\
24\end{array}$ \\
\hline
\end{tabular}

It will be seen that, as compared with their prewar rate, the women in 1941 experienced nearly twice as many accidents, whilst the other groups showed a very much smaller increase. The change in the character of the women's work is suggested by a table in the 1943 Report, which showed that the number of women employed on machine-making rose from 650 in 1938 to 23,435 in 1943 , and those on aircraft, from 43 to 6,612 .

Young Persons. Though young persons (under 18 years old) are usually assigned to less risky occupations than adults, they incur a relatively greater proportion of accidents. From the 1938 Report we find that between 1928 and 1938 all the young persons employed experienced about 8 per cent. more accidents, per head, than the adults.

Young persons have the advantage of a considerably smaller fatality rate than adults. The data adduced from the 1934 Report (Table 3) show that the rate for boys was only half that for men, and 
though it was slightly higher for girls than for women, the female sex, as a whole, had a rate only a fifteenth as great as that of the male sex.

TABLE 3

FATAL AND NON-FATAL ACCIDENT RATES PER 100,000 EMPLOYED

\begin{tabular}{|c|c|c|c|}
\hline & $\begin{array}{c}\text { Fatal } \\
\text { accidents }\end{array}$ & $\begin{array}{l}\text { Non- } \\
\text { fatal } \\
\text { accidents }\end{array}$ & $\begin{array}{l}\text { Ratio of } \\
\text { fatal to } \\
\text { non-fatal } \\
\text { accidents }\end{array}$ \\
\hline $\begin{array}{l}\text { Adults } \\
\text { Young } \\
\text { persons }\end{array}\left\{\begin{array}{l}\text { males } \\
\text { females } \\
\text { males } \\
\text { females }\end{array}\right.$ & $\begin{array}{r}20 \cdot 3 \\
1 \cdot 2 \\
11 \cdot 1 \\
1 \cdot 6\end{array}$ & $\begin{array}{r}3530 \\
938 \\
4890 \\
1552\end{array}$ & $\begin{array}{l}1 \text { to } 174 \\
1 \text { to } 782 \\
1 \text { to } 440 \\
1 \text { to } 970\end{array}$ \\
\hline
\end{tabular}

The fatality rate of factory workers has gradually dwindled during the course of the present century, being 31 per 100,000 men employed in 1901-1907, and only 16 per 100,000 in 1938 (cf. 1938 Report). This was due in large part to the better safeguarding of machinery.

The fatality rate varies enormously in different industries. For instance in 1932 the ratio of fatal to non-fatal was 1 to 27 in workers employed on building construction and 1 to 73 in dock workers, whilst at the other extreme it was 1 to 402 in workers in the light metal trades and 1 to 434 in those engaged in metal founding.

Minor Accidents. In addition to compensated accidents industrial workers are liable to suffer almost innumerable minor accidents which do not involve much lost time but inevitably cause a good deal of temporary pain and discomfort. The ratio of uncompensated to compensated accidents varies greatly in different occupations, but we may perhaps assume that on an average the uncompensated are about forty times as numerous as the compensated. Thus at the Stanton Iron Works (1933) the 5000 men investigated in 1923-1932 showed a ratio of 20 to 1 , at three other British works the ratio for 9000 workers was 73 to 1 , and at an American factory it was 48 to 1 .

\section{Causes of Accidents}

The numerous causes of accidents are discussed in subsequent pages, but it is convenient to quote here some statistical information as it will help to emphasize the extreme importance of nonmechanical factors as compared with those due to machinery. The data in Table 4 relate to the year 1928, and it will be seen that whilst in all the factory accidents put together there were, on an average, 2,780 accidents per 100,000 employed, the rate varied from 516 to 11,393 in the sample industries recorded. Of the total accidents, about a fifth were due to machinery moved by mechanical power, the remainder being due to the personal qualities of the employees. It follows that the prevention of accidents by mechanical means, though of great importance, cannot at best effect more than a very limited reduction in the number of accidents incurred. In 1925 Sir Gerald Bellhouse maintained that 'not more than one-third (of the accidents) have anything to do with machinery whatever, and out of that third we estimate at the Home Office that a third would be prevented by the provision of physical safeguards.' An actual investigation of 3000 consecutive accidents * gave a still lower proportion, for it appeared that fourfifths of them were non-mechanical, and that of the mechanical accidents less than half could have been prevented by the most complete provision of safeguards.

Of the non-mechanical causes, ' Handling goods in manufacture' was easily the commonest cause of accident, whilst each of the other three causes designated was responsible for about half the number of accidents. The relative proportions of these four chief causes naturally differed very greatly in various industries.

\section{Personal Factors in Accident Causation}

Age and Experience. Perhaps the most important factors of all in accident causation relate to the age and experience of the workers. Usually the two factors are so closely bound together that it is impossible to disentangle them. Most manual workers begin their factory experience shortly after leaving school at the age of 14, though they frequently move from one industry to another at later ages. Still, we cannot easily get clear-cut statistics

* Industr. Welfare, 1926, p. 169.

FACTORY ACCIDENTS PER 100,000 PERSONS EMPLOYED (1928)

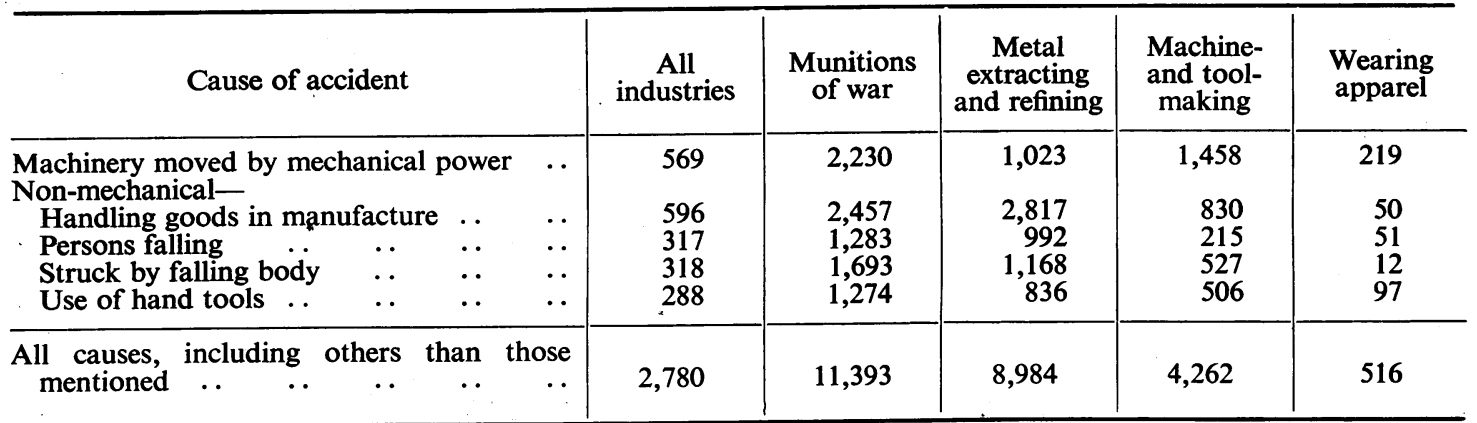


about inexperienced workers who have entered industry for the first time at later ages, except in war-time and, as previously mentioned, the information then available is complicated by the fact that many of the workers have beeen allotted to more dangerous occupations than those usually followed in peace-time.

If we for the time being ignore the effects of age as distinct from experience, we have plenty of striking information, and none better than that provided by the Factory Department. In the Annual Report for 1937 Bennett illustrates his article with two charts, one of which is here reproduced (fig. 1). It will be seen that in the first halfyear worked by the boys and girls (in a group of 65

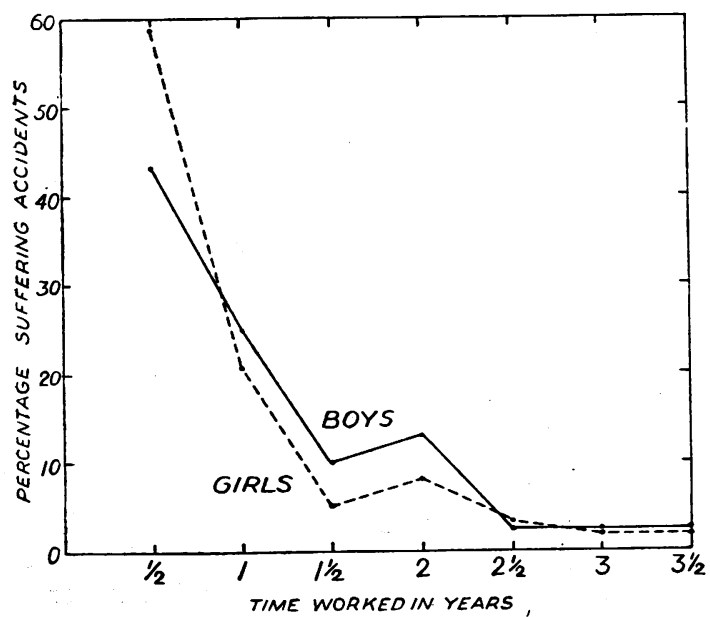

FIG. 1.-Relationship of accidents incurred by young persons to years of experience.

factories) about 50 per cent. suffered an accident. In the next half-year the proportion fell to 23 per cent. and, after two years' experience, to about 3 per cent. A detailed analysis showed that in 44 per cent. of all the accidents the young worker was to be held responsible, and in 36 per cent. of them the responsibility was on the firm. In the remaining 20 per cent. no blame could be attached to either party.

A great reduction of accidents can be effected by preliminary training and supervision. At one firm, for instance, all boys applying for employment were carefully selected, and the boys were passed through the works school where their attention was focussed on tidiness, suitable clothing, machines and their dangers, adjustment of guards, shafting and its dangers, etc. As a result, the accidents to the boys were nearly halved between 1936 and 1937. At another firm a series of lectures was held, and the young persons were given personal instruction with regard to the proper use of lathes, drills, milling machines, etc., whilst tours of the works were arranged in order to show the risks in special classes

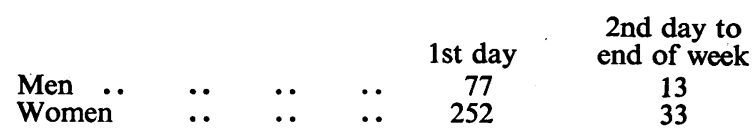

of machines. Also each apprentice was given a booklet containing safety hints.

Unfortunately, as Bennett emphasizes, such training schemes as those mentioned are not common in our factories, and it is distressing to find that so many accidents to juveniles can clearly be attributed to lack of training and supervision or to unsuitable training having regard to the dangerous nature of the work. An outstanding instance of such lack of training is provided by Chaney and Hanna (1918). It relates to persons engaged on stamping presses, and from the data adduced we see that on the first day the women incurred about eight times as many accidents as they did per day during the rest of the week, and $\mathbf{7 7 0}$ times as many accidents as they did

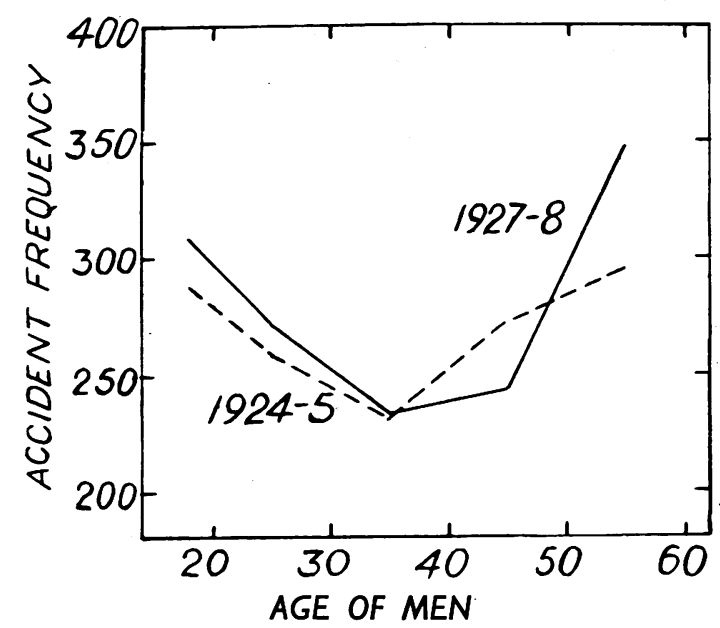

FIG. 2.-Accident frequency of coal miners in relation to age

per day after six months' experience. The men's liability varied on similar lines, though not to so striking an extent.

In some cases it is possible to infer, to some extent, the different effects of age and experience, as in the observations made by Vernon, Bedford and Warner (1928 and 1931) on the compensation accidents incurred by over 18,000 coal miners during two two-year periods. The results obtained with coal-face workers are shown in fig. 2 , and it will be seen that the accident rate (per 1000 men per year) fell considerably with age unil the men were 30-39 years old, and that in subsequent years they rapidly increased with age. This increase must have been due to the fatiguing effects of the very arduous work on the men, which more than neutralized the favouring effects of greater experience.

It is a matter of common knowledge that young people tend to be more irresponsible and careless than older people; also they get tired more quickly, but it is almost impossible to estimate the relative importance of these factors as contrasted with those of increased experience and skill.

$\begin{array}{ccc}\begin{array}{c}\text { 2nd week to } \\ \text { end of month }\end{array} & \begin{array}{c}\text { 2nd month to } \\ \text { end of } 6 \text { months }\end{array} & \begin{array}{c}\text { 7th month to } \\ \text { end of year }\end{array} \\ 3 & 0.8 & 0.2 \\ 4 & 0.7 & 0.3\end{array}$


It must be remembered that workers who have substantially reduced their accident rate in one occupation as the result of experience have no similar degree of immunity if they change to another occupation. The risks incurred are generally of a different kind, and the worker may have to pass through another period of ' trial and error,' though his previous experience of factory life in general will be of value.

General Health. Liability to incur accidents is influenced by the general state of health of the workers. For instance, Newbold (1926) found that in the various factories studied by her there was a distinct relationship between accident frequency and the number of minor sicknesses from headache, colds, sore throat, indigestion, faintness, etc., treated at the ambulance room. This relationship is shown graphically in fig. 3, which relates to a group of 352

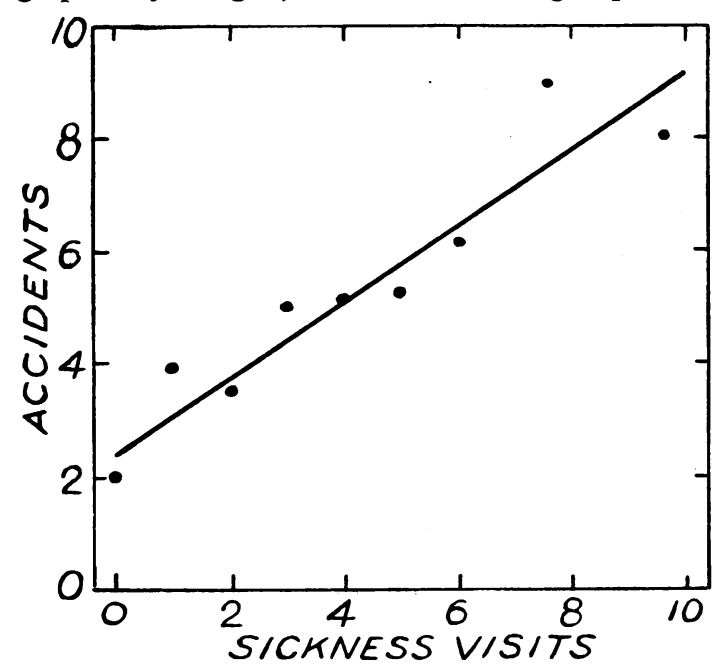

FIG. 3.-Relationship between accidents incurred by metal workers and sickness visits to ambulance room

men working in the metal departments of a motor car factory. During a 6-month period they incurred 1330 accidents in all, and the graph shows that whilst the men who did not visit the ambulance room for sickness at any time suffered two accidents, on an average, those who paid one or two visits suffered three or four accidents, those who paid three to five visits suffered about five accidents, and those who paid eight or ten visits suffered about eight accidents. The data seemed to be rather an indication of 'tendency to report sickness' or of disinclination to work, than of 'tendency to be sick.' They appeared to indicate lower general health and vitality.

The Chief Inspector of Factories (1942) states that welfare departments have often noted the close connection between sickness and accident rates, and he points out that this is an additional reason for more adequate medical supervision.

Accident Proneness. It is well known that some persons are habitually clumsy with their hands, and frequently break the articles they handle, i.e. they have accidents with them. Also they often incur minor injuries such as cuts and scratches on their hands. In other words, they are accident-prone. This condition was first studied scientifically by Greenwood and Woods (1919), who investigated the frequency with which accidents were incurred in groups of women engaged on various operations required in the manufacture of shells. Though all the women in each group were exposed to a similar degree of risk, it was found that whilst many of them experienced no accidents at all, others had many more accidents than could be accounted for by chance. For instance, in a group of 648 women 448 of them in a given period incurred no accidents, 132 incurred one accident, 42 incurred two accidents, and 26 incurred three to five accidents. It was shown by mathematical analysis that if the accidents had been distributed by simple chance only eight of the women would have incurred these multiple accidents, so the excess was due to some other factor. No estimate was made of the state of health of the women, and no doubt this condition may have been responsible for some of the accidents, but an extension of the observations on a large scale by other investigators has proved that the state of accident proneness genuinely exists in many perfectly healthy persons.

In this country Farmer and Chambers (1926, 1929 and 1939) and Farmer, Chambers and Kirk (1933) have for many years been investigating the condition of accident proneness with a view to finding some test or tests which would serve as a means of identifying the affected persons in groups of industrial workers. They found that the probable number of such persons ranges from about 10 to 25 per cent. of the total.* In order to obtain reliable information, they chose large groups of subjects whose age and experience were similar, and of whom adequate accident records could be obtained for a number of years. These subjects were for the most part apprentices of the Royal Air Force and Dockyards, and in a group of 600 of them it was found that the 25 per cent. who did worst at the 'aesthetokinetic' tests employed (which involved rapid hand and eye co-ordination) the accident rate was double that of the remaining 75 per cent. Later on 1700 subjects were tested in the same way and gave a similar result, but tests on qualities such as mechanical aptitude and linguistic intelligence did not show such a close relationship with accident proneness. When the aesthetokinetic tests were applied to other groups of men besides those mentioned they gave a similar result in so far as the men were skilled workers, but unskilled workers did not show any relation between accident rate and the tests. This was probably because their occupations were less dependent on rapid and accurate co-ordination.

An analysis of the accident records of some 14,000 workers in various trades showed that in most of them those who had an undue number of

* Cf. Emergency Rep. No. 3, Industr. Hlth. Res. Bd. 1942 : The Personal Factor in Accidents. 
minor accidents also had an undue number of major accidents. Now in some occupations the risk of a major accident is much greater than in others, so it would be well to keep such workers as were known to be accident-prone in occupations where they could not incur more than minor accidents. Unfortunately very few firms subject their new employees to psychological tests before assigning them to one occupation or another, but in the absence of such tests it would be possible to sift them roughly by putting them, for a time, on occupations free from major risks, and only after they had shown themselves to be reasonably free from accident proneness, to transfer them to more dangerous occupations. Best of all would it be to use the psychological tests on all new entrants into industry, and to keep a subsequent look out for signs of accident proneness in the selected workers. Thus, the tests do not afford an absolutely reliable criterion, but only a probable indication.

The identification of accident-prone persons is especially important in relation to motor driving, and numbers of observations on the responses of drivers to psychological tests have been made. In an investigation on 2300 men employed in driving cars on the Boston elevated railway, Slocombe and Brakeman (1930) found that 20 per cent. of the men had an accident rate three and a half times greater than the remainder. When samples of these men were given psychological tests it was found that the high-accident men had a poor test score four times more frequently than the low-accident men.

Accident proneness is greatly influenced by the mental attitude of the subjects. The accidentprone are apt to be insubordinate, temperamentally excitable and to show a tendency to get flustered in an emergency. These and other defects of personality indicate a lack of aptitude on the part of the subjects for their occupation.

\section{Factory Conditions}

Factory workers are inevitably dependent on the management for the conditions under which they have to work, and if these conditions are such as to place an undue strain upon their physical or mental powers, they react by suffering an increase of accidents. Fatigue is normally the most potent cause of excessive accidents, and this fatigue is generally due to the hours of labour being too long. Hence we may conveniently study fatigue and hours of work in conjunction.

Hours of Work and Fatigue. We sometimes hear of fatal accidents due to motor drivers who have been called upon to drive long distances for many hours on end, and make the return journey after a totally insufficient interval of sleep. These cases of extreme fatigue are exceptional, but it follows that smaller degrees of fatigue are likely to increase accidents in some degree. Investigations on industrial workers have shown that such an increase happens very frequently, and the excessive hours of work which were imposed during the last war, and to a less extent in the present one, afford striking proof of the influence of hours of work on accidents. Vernon (1918) made a detailed investigation at several munition factories, and especially at a factory where the majority of the 10,000 workers were engaged in making fuzes. At first they were on a 12-hour day and 75-hour week, but later on they were changed over to a 10-hour day. About 70 per cent. of all the accidents incurred consisted of cuts, and as the workers usually got them dressed immediately after they suffered them, they afforded a reliable index of the times of accident incidence. A comparison of the accident frequency per shift during the two systems of hours gave the following results:

\begin{tabular}{ccccc} 
& & $\begin{array}{c}\text { Relative accident } \\
\text { frequency per } \\
\text { shift }\end{array}$ & \multicolumn{2}{c}{$\begin{array}{c}\text { Percentage of after } \\
\text { noon accidents on } \\
\text { morning accidents }\end{array}$} \\
12-hour day ... & 114 & 273 & 107 & 145 \\
10-hour day... & 100 & 100 & 108 & 117
\end{tabular}

It will be seen that in the men the accident frequency was only 14 per cent. greater during the 12-hour day than during the 10-hour day, and if allowance is made for the longer hours worked the rate per hour was slightly smaller. Among the women, however, the accidents were nearly three times as numerous during the 12-hour day as they were subsequently, or more than twice as numerous if allowance is made for the longer hours worked.

The right half of the table gives a comparison of the accident rate in the afternoon, when the workers were no longer fresh, with that observed in the morning, and we see that during the 12-hour day period the men's rate increased 7 per cent., whilst that of the women increased 45 per cent. In the 10-hour day period, however, the afternoon increase shown by the women did not greatly exceed that shown by the men. Hence these data, taken as a whole, suggest that the men suffered little from overfatigue during the 12-hour day, whilst the women were greatly affected. Medical evidence obtained from the records of the ambulance room emphasized this reaction of the women, for it appeared that during the 12-hour day the women were treated for faintness nine times more frequently than the men, and were given sal-volatile twenty-three times more frequently. When the working hours were reduced to 10 a day the number of cases fell off greatly, and the women were treated only about three times more frequently than the men.

It has been known for a long time that there is usually a gradual increase of accidents during the course of the work spells, and this increase has often been ascribed to the effects of fatigue. The fuze factory accidents afforded a specially favourable opportunity for testing this view, because accident rates were obtainable when the workers were on night shift as well as on day shift. Fig. 4 shows the variations in the accident rate from hour to hour of day and night. It will be seen that during the 12-hour day the women's accidents underwent a fivefold rise in the course of the morning work 


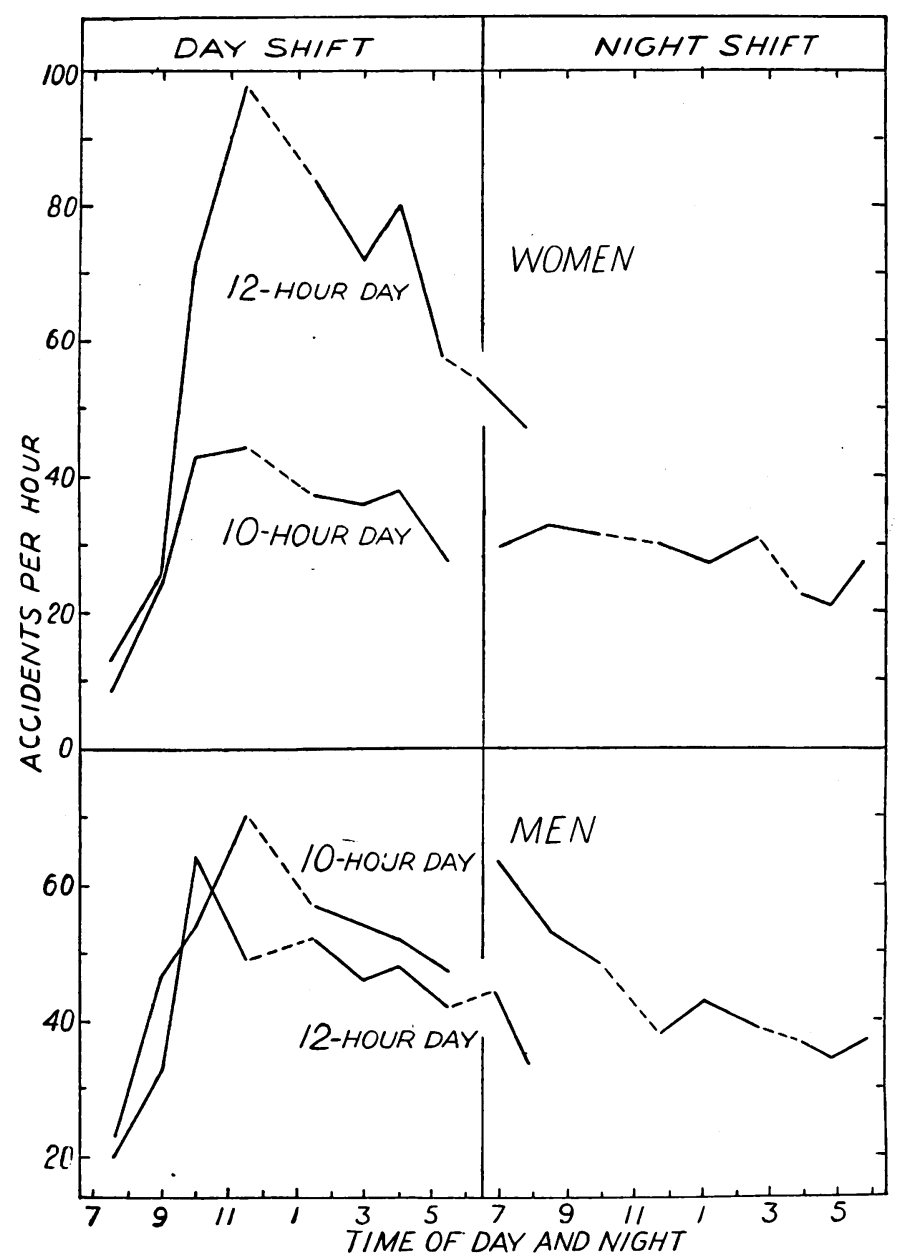

FIG. 4.-Hourly variations in accidents

spell, and kept very high during the afternoon work spell. During the 10-hour day, however, there was only a threefold rise, and the afternoon accident rate was only half as great as it was in the 12-hour day. The men, on the other hand, showed only a twofold rise during the morning spell, both in the 12-hour and the 10-hour day, and in the afternoon spell their accident rate under the two systems of hours likewise corresponded roughly.

How much of the morning rise of accidents in the men and women was due to fatigue, and how much to other factors? The night shift accidents appeared at first sight to indicate that it was not due to fatigue at all. These night accidents were incurred by the same groups of men and women, for they worked alternate fortnights of day and night shift (10 $\frac{1}{2}$ hours by night), and it will be seen that in both sexes the accidents were at a maximum when they started work, and gradually diminished down to a minimum as the night wore through. The apparent contradiction with the day shift is attributed to the mental state of the workers. When on night shift they usually got up three or four hours before they were due at the factory, and often spent these hours in shopping or amusements.
Consequently they came to the factory in a lively state, but they gradually calmed down during the course of the night as they had nothing but an unexhilarating breakfast and bed to look forward to. They therefore became more and more attentive to their work, and less liable to accidents. The day shift, on the other hand, got up as late as possible, and after a hurried breakfast (or none at all), they arrived at the factory in a depressed condition. However, they brightened up gradually in the course of the morning, as they generally got a cup of tea, and they had their dinner break to look forward to. In consequence, they became less attentive to their work and accidents multiplied. It will be noted that the relative increase of accidents by day was more marked than the decrease by night, owing to fatigue augmenting the effect of the mental condition of the workers in the one case, and acting in the reverse manner in the other case.

This apparently contradictory result for day and night shifts has been observed at other factories, and it serves to emphasize the important influence which the mental state of the workers exerts on their accident liability. We know that what is commonly spoken of as carelessness is a frequent 
cause of accidents, but it must be borne in mind that the degree of care and attention exercised when carrying on an occupation is relative and not absolute. No one can concentrate his maximal degree of mental energy on a task for more than a very short period. Moderate concentration is possible for a much longer time, but almost inevitably the attention fluctuates, especially in workers engaged on monotonous repetition work, and the greater the fatigue the less their alertness.

Atmospheric Conditions. The atmospheric conditions under which workers have to carry on their labours may have a considerable influence on accident frequency. For instance, Osborne and Vernon (1922) found that in munition factories (for fuzes and shells) the minor accidents incurred were relatively frequent at low temperatures, but with rise of temperature they gradually sank till they reached a minimum at $65^{\circ}-69^{\circ}$. Then they rose again more and more with further rise of temperature, as can be seen in fig. 5. The explana-

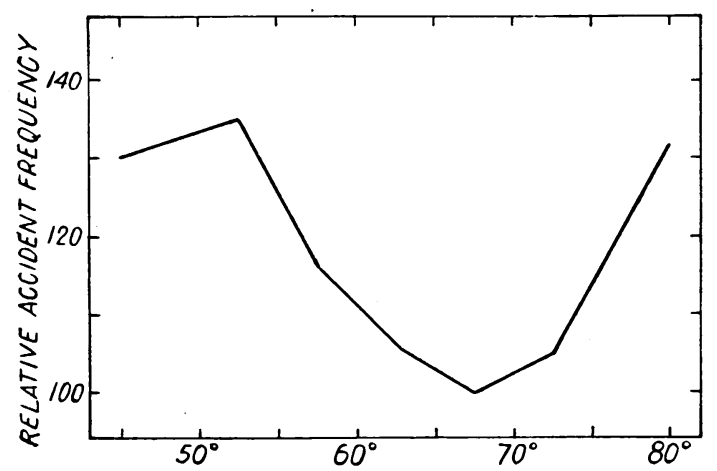

Fig. 5.-Accident frequency in relation to temperature

tion appears to be due to the fact that at low temperatures the hands of the workers lose some of their dexterity because they get numb owing to contact with the metal objects manufactured and with the stream of soapy water in which most latheproduced articles are turned. At high temperatures, on the other hand, the workers tend to get more inattentive and more easily fatigued.

The effects of high temperatures on accident liability were even better shown in the observations of Vernon, Bedford and Warner (1928 and 1931) on coal miners. Data were obtained at temperatures ranging from a minimum of $61.5^{\circ}$ (d.b.) and $60.0^{\circ}$ (w.b.) to a maximum of $85.4^{\circ}$ (d.b.) and $75.7^{\circ}$ (w.b.), and the averages showed that at a dry bulb temperature of $82 \cdot 8^{\circ}$ the coal-face workers suffered 30-77 per cent. more accidents than at $63 \cdot 9^{\circ}$.

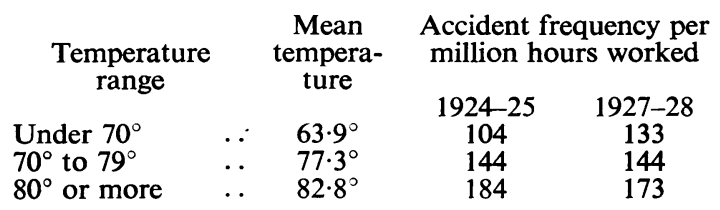

These data are the averages of the thousands of compensation accidents suffered by the miners, and their periods of disablement ranged from a few days to many months. When the accidents were classified according as the period of compensation was (a) under 10 days, (b) from 10 to 19 days, and (c) for 20 or more days, it was found that the relative frequency rates observed at various temperatures showed very striking differences. The frequency of the accidents causing less than 10 days' disablement rose very rapidly with temperature and was three or four times greater at the highest temperatures than at the lowest. The more severe accidents, causing 10-19 days' disablement, rose much less rapidly, whilst the severe accidents, causing 20 or more days' disablement, were only 27 per cent. more numerous at the highest temperatures. That is to say, the decision of an injured miner to go on to compensation was influenced by considerations other than those dependent on the plain facts of incurring an injury and recovering

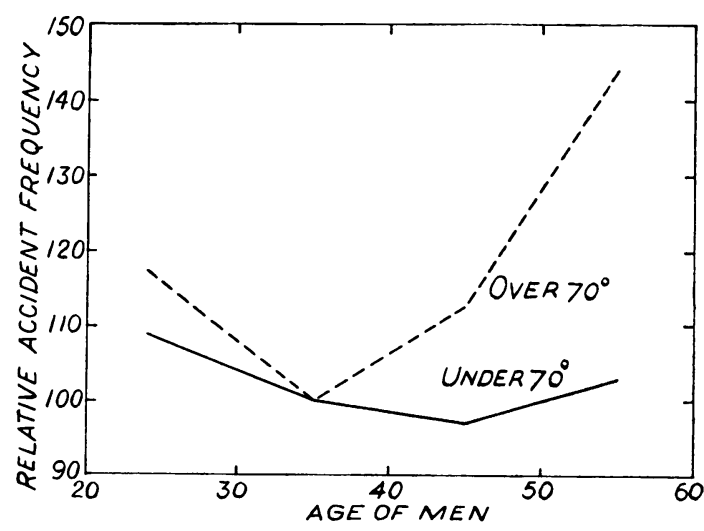

Frg. 6.-Relative accident frequency of coal miners in relation to age and temperature of mine

from it. A man who receives a severe injury is bound to go on to compensation whatever the temperature, but if he receives a minor injury he in any case gets no compensation for the first three days, and at the end of that time his decision is largely influenced by his recollection of the conditions under which he was working. If they were unpleasantly hot and induced extra fatigue he may decide to take a few days more away from work in which to recuperate, and he consequently goes on to compensation.

High temperatures were much more fatiguing to the older men than to the younger men, as is indicated in fig. 6 . We see that in men working at temperatures below $70^{\circ}$ there was very little variation of accident liability with age, and only men of 50 years and upwards showed a slight increase. At temperatures over $70^{\circ}$, however, the men reached their minimum at the ages of $30-39$, and showed a marked increase as they got older.

Comfortable atmospheric conditions, with a low accident liability, depend not only on the dry and wet bulb temperature, but on the degree of air 
movement. For most industrial work this should be moderate, but the more arduous the work the greater the requisite degree of movement.

Lighting. Defective lighting, whether artificial or natural, may have a considerable influence on accident liability, though it is difficult to obtain clear-cut evidence of the effect. For instance, the Departmental Committee on Lighting in Factories (1915) showed that in a number of industries, and especially in shipyards and docks, accidents were more numerous in the winter than in the summer, with intermediate rates in spring and autumn. The variations were attributed largely to the degrees of artificial and natural lighting to which the workers were exposed at different times of the year, but they must also have been influenced, to an unknown extent, by temperature variations.

The standards of lighting required by the statutory regulations now in force have specific reference to the safety of the workers, and in consequence, as Weston (1944) points out, the better the conditions of factory lighting, up to the point of maximum efficiency of vision, the better the insurance against accidents.

\section{Psychology of Accident Prevention}

We have seen that accident prevention is mainly a personal problem, and it depends on the creation of habits, both conscious and unconscious, which conduce to the avoidance of unnecessary risks. No one can possibly keep himself always at the maximum degree of alertness and attention, and it inevitably follows that when attention relaxes liability to accident increases. Everyone should therefore endeavour to acquire the habit of increasing his alertness at times when specially exposed to risk, and this habit is best acquired by long continued education. It is sometimes maintained that the encouragement of a safety habit of mind is likely to lead to cowardice and over-anxiety, but this should only happen if the habit is developed on the wrong lines. It is usually possible to distinguish between legitimate risks and mere foolhardiness, and to instruct young persons in such a way that they are able to decide for themselves to which class a given accident risk belongs. For instance, by systematic instruction the number of children killed in road accidents in London was kept down almost to a steady rate from 1924 onwards till the war, though it greatly increased in Britain as a whole, owing to neglect of wellorganized instruction.

We have seen that young persons who, after leaving school at the age of 14 , for the most part pass straight into various forms of industrial work, are at once exposed to a number of new risks of which they are totally ignorant. If not specially instructed, they take years to acquire the necessary experience which teaches them how to avoid these risks. Hence it is most desirable that they should have a special course of safety instruction before they are subjected to them. Almost inevitably the character of their occupation changes as they get older, and they are therefore subjected to fresh and hitherto unknown risks. It is true that they have already acquired some general knowledge about their avoidance, but this is not enough. They must be further educated, and moreover, be continually educated, so that they may not forget the lessons already learnt.

The instruction of the workers generally takes the form of a 'safety campaign,' or a ' safety first movement,' as it was formerly designated. A scheme was introduced in this country by the late Lord Leverhulme as long ago as $\mathbf{1 8 9 2}$, and various plans have been urged by factory inspectors for many years past. Owing to the special liability likely to be incurred by fresh and inexperienced workers during the war, the Factory Department has made a new departure ( $c f$. the 1940 Report), and has secured the practical assistance of the Royal Society for the Prevention of Accidents. Their scheme includes the provision, free of charge, to all occupiers of considerable factories of printed and pictorial matter designed to educate and influence management and workers alike. The managerial staffs receive a monthly bulletin, and the workers, weekly posters, both drawing attention to specific hazards and aiming to cultivate the sense of personal alertness and responsibility. In the first instance about $\mathbf{5 0 0 0}$ factories were served, and the heads of Technical Schools, Government Training Centres and Juvenile Instruction Centres also participate. As the Chief Inspector insists, it is a fundamental part of the campaign that managements must cooperate actively in making use of it. The mere affixing of pictorial posters will of itself accomplish comparatively little. In addition, a works accident prevention committee ought to be set up and a safety officer appointed, who will devote the whole or part of his time to stimulating and controlling the activities of the committee. The committee must not only be supported by the firm, but the workers themselves ought to be directly represented on it.

Other war-time innovations (cf. 1942 Report) consist in the production of safety films both by the government and by private firms. Courses of lectures for safety officers have been held at Oxford, and there has been an increased activity of the local safety committees in many areas, especially in large centres such as Manchester and Birmingham. Again, lectures are being given to those actually working on the floor of the factory, and other lectures to workpeople who are being trained as foremen. At one large government factory engaged mainly on engineering work continuous series of lectures were given during 1942 to new women entrants. The women were given a preliminary training course of four days, and the district staff of the Factory Department gave one of the lectures. The accident figures show a striking result, the frequency rate of accidents to women who have attended the lectures being less than half the rate for those who have not attended.

In the coal-mining industry a safety campaign 
was instituted in 1922. It is run on somewhat similar lines to that in factories, but the colliery manager has a much more difficult problem than the average factory manager. He is waging a continuous war against nature. He may have to fight gas, water, a bad roof, spontaneous combustion and other dangers over the source of which he has little control. Nevertheless the inspectors of mines maintain that between 30 and 40 per cent. of the fatal accidents, and 50 per cent. of the non-fatal accidents, are preventable. Unfortunately supervision of the miners is very difficult, and the safety movement does not seem to have been adopted with much enthusiasm.

\section{Frequency Rates and Severity Rates}

In order to be able to compare the accident frequency observed in various factories it is important that the rates should be calculated on the same plan, and be in terms of the number of hours worked, or the hours of ' exposure to risk.' In America and many other countries the standard frequency rate is calculated for a million hours of exposure. This may yield an inconveniently large figure in some industries, and in this country the Factory Department now calculates the rate for 100,000 hours of exposure. Another source of error arises from the choice of the class of accidents to be included. Should all the minor accidents be taken account of, even if they involve a visit of only a few minutes' duration to the ambulance room? The Chief Inspector (1942 Report) requests that the standard adopted by the International Labour Office be kept to strictly, viz., all accidents causing loss of time beyond the day or shift on which the accident occurred.

Accidents vary considerably in severity in different industries. For instance, mining and quarrying accidents are, on the whole, two to four times more severe-as judged by disability-than factory accidents. As we wish to be informed of the actual working time lost, it is desirable to calculate the accidents in terms of severity rates as well as of frequency rates. The rate usually chosen is the number of days lost per 1000 hours of exposure to risk. The information from which frequency and severity rates are calculated should be recorded on the 'sickness absence' cards in accordance with the scheme promulgated by the Industrial Health Research Board (1944).

The reports of the Factory Department often record statistical data showing the effects of safety organizations on accident rates. For instance the 1931 report quotes the following figures obtained at an iron works (the frequency rates being per million hours worked):

\begin{tabular}{|c|c|c|c|c|}
\hline & 1927 & 1928 & 1929 & 1930 \\
\hline ate & . 96.9 & $92 \cdot 7$ & $78 \cdot 5$ & $74 \cdot 8$ \\
\hline Sev & $2 \cdot 4$ & 2.5 & $2 \cdot 3$ & 1.9 \\
\hline
\end{tabular}

Though factory inspectors do all they can to stimulate the safety movement, safety campaigns appear to have been adopted by only a small minority of the industrial firms in this country. Of the large firms, with over 1000 employees, only 1 in 5 were (in 1934) members of the National Safety First Association (now the Royal Society for the Prevention of Accidents), whilst of the smaller firms, with 26 to 1000 employees, only 1 in 200 were members.

\section{Protection of the Body}

In addition to protecting machinery by proper safeguards, the worker himself ought to receive protection by suitable clothing for his body, and (in many cases) by goggles for his eyes. The management is to a large extent responsible for seeing that the clothing worn is appropriate, but the worker has to play a part, and not evade the regulations laid down. Loose clothing is apt to get caught in moving machinery, and, in the case of women workers, the hair may get caught unless it is confined by a proper cap. A well-illustrated pamphlet on protective clothing has been published by the Factory Department (1940). This includes information about the special protection of the face, hands and arms, and feet and legs, necessary in certain industries.

In many industries protection of the eyes is more important than the protection of all the other portions of the body taken together. It is stated by Cridland (1929) that in this country about 10 per cent. of all cases of blindness are due to accidents, most of which are incurred in industry, and American statistics show that 13.5 per cent. of all cases of blindness are due to accidents. The success of safety measures in reducing eye accidents is shown by the statistics of the United States Steel Corporation (J. industr. Hyg., 1925, 7, 36). The firm provided 44,000 pair of goggles, or about one pair for every five or six men employed, and as a result the eye accidents were reduced nearly 60 per cent.

\section{REFERENCES}

Bellhouse, Gerald (1925). Safety First, 1, 166 Bennett, S. R. (1938). Ann. Rep. H.M. Chief Inspector of Factories for 1937, p. 41.

Chaney, L. W., and Hanna, H. S. (1918). Bull. No. 234, U.S. Dept. Labour, pp. 131 and 161 .

Cridland, B. (1929). Brit. med. J., 2, 615

Departmental Committee on Lighting in Factories. 1915. First Rep.

Rep.
Emergency Rep. No. 3 Industr. Hlth. Res. Bd., 1942. The Personal Factor in Accidents.

Farmer, E., and Chambers, E. G. (1926, 1929 and 1939). Reps. Nos. 38, 55, 84, Industr. Hlth. Res. Bd. , and Kirk, F. J. (1933). Rep. No. 68 Industr. Hlth. Res. Bd.

Greenwood, M., and Woods, H. M. (1919). Rep. No. 4 Industr. Fatig. Res. Bd.

Newbold, E. M. (1926). Rep. No. 34 Industr. Fatig. Res. Bd.

Osborne, E. E., and Vernon, H. M. (1922). Rep. No. 19 Industr. Fatig. Res. Bd.

Protective Clothing for Persons Employed in Factories (1940). Welf. Pamphlet No. 1, 3rd Ed. (reprinted 1942). Min. of Lab., H.M.S.O. Lond.

Slocombe, C. S., and Brakeman, E. E. (1930). Brit. J. Psychol., 21, 29.

Stanton Iron Works (1933). Industr. Welfare, Feb., p. 5.

The Recording of Sickness Absence in Industry. 1944. Rep. No. 85 Industr. Hith. Res. Bd.

Vernon, H. M. (1918). Memo. No. 21, Hlth. Munition Workers Committee.

Bedford, T., and Warner, C. G. (1928 and 1931). Reps. Nos. 51, 62, Industr. Hith. Res. Bd.

Weston, H. C. (1944). Brit. J. industr. Med., 1, 180. 